$-$

Global Journals

(4)

\title{
Not Only What is Written Counts! Touchscreen Enhancing Our Cognition and Language
}

By Marcelo Bairral

Federal Rural University of Rio de Janeiro (UFRRJ)

Abstract- By bringing contributions from cognitive science and neuroscience, this article enhances the gestures approach including, manipulations on mobile devices as a new way of communicating and thinking. The paper reflects on the cognitive and linguistic implications that smartphones or tablets can bring to learning in general and mathematical education in particular. Both thinking and mathematics are dynamic. Through two examples from daily life, I advocate the need to understand the development of mathematical thinking as a conjunction of touchscreen, gesture, speech, dragging, writing, pictorial-register, etc. Taking into account the context of production, this bundle has a significant role in the linguistic-cognitive spectrum of humans.

Keywords: smartphone, tablets, language, cognition, mathematics education.

GJHSS-G Classification: FOR Code: 200399

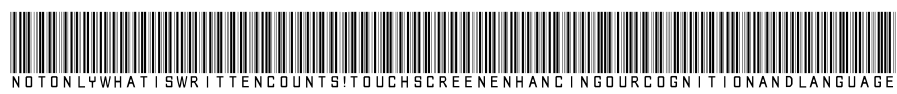

Strictly as per the compliance and regulations of:

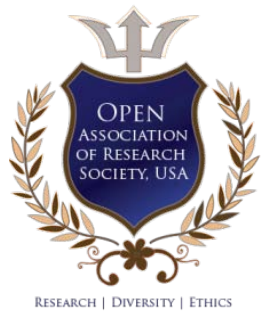

(C) 2020. Marcelo Bairral. This is a research/review paper, distributed under the terms of the Creative Commons AttributionNoncommercial 3.0 Unported License http://creativecommons.org/licenses/by-nc/3.0/), permitting all non-commercial use, distribution, and reproduction in any medium, provided the original work is properly cited. 


\title{
Not Only What is Written Counts! Touchscreen Enhancing Our Cognition and Language
}

\author{
Marcelo Bairral
}

\begin{abstract}
By bringing contributions from cognitive science and neuroscience, this article enhances the gestures approach including, manipulations on mobile devices as a new way of communicating and thinking. The paper reflects on the cognitive and linguistic implications that smartphones or tablets can bring to learning in general and mathematical education in particular. Both thinking and mathematics are dynamic. Through two examples from daily life, I advocate the need to understand the development of mathematical thinking as a conjunction of touchscreen, gesture, speech, dragging, writing, pictorial-register, etc. Taking into account the context of production, this bundle has a significant role in the linguistic-cognitive spectrum of humans.
\end{abstract}

Keywords: smartphone, tablets, language, cognition, mathematics education.

\section{InTRODUCTION}

$\mathrm{M}$ obile devices with touchscreen (MDT), tablets, and smartphones have been taking an increasingly important role in the lives of individuals, teaching and learning, and also in research processes. As tablets and particularly smartphones are extensions of our bodies, we have come to perform activities in our lives, which we would not have done without them. These are the types of situations that have stimulated me in my research group on mathematics education.

The history of humankind is continuously creating technologies, and these technologies, synergistically, keep re-dimensioning us. Our minds, bodies and physical environment work in constant synergy. In the physical spaces we move through, we deal with technological, cognitive, cultural resources. Among those resources, devices such as smartphones or tablets provide, together with their mobility, - which they share with other artifacts, like cordless telephones, for instance -, a convergence of media in a single device, and ubiquity (the possibility to surf different spaces thanks to their connectivity).

In a previous article (Bairral, 2019) ${ }^{2}$ I illustrate six dimensions (contemporaneity, socio-technology, neurocognitive, perceptive-affective, discoursecommunicative, political-pedagogical) that can be considered when MDT comes into play in teaching,

Author: Senior professor at Federal Rural University of Rio de Janeiro (UFRRJ).e-mail: mbairral@ufrrj.br

\footnotetext{
${ }^{1}$ www.gepeticem.ufrrj.br

${ }^{2}$ From a research project granted by National Council for Scientific and Technological Development (CNPq, Brazil).
}

learning or research in STEM $^{3}$. In this article, I consider the cognitive and linguistic contributions that smartphones or tablets can bestow upon learning in general and mathematical teaching in particular. Specifically, the aim of this paper is in part to enhance the gestures approach proposed by McNeill (McNeill, 1995, 2002), adding the different forms of manipulation ${ }^{4}$ in our communicative spectrum. I am presenting some singularities of MDT. I am also determining some peculiarities of screen touching and providing illustrations with two daily situations (video assistant referee and rotating movements) that have inspired the reflections that follow.

Some intertwined principles that substantiate the ideas developed in this article are: i) manipulations on screen represent a new form of language manifestation and have come to integrate our embodied cognition; ii)acknowledging that a new way of communication and interaction implies assuming our body as a motor and propeller of our thinking, in constant symbiosis and reconfiguration with the environment; iii) since human actions, as well as mathematical concepts, are multimodal in their development and understanding, we need to consider the conjunction of gesture + speech + construction-onthe-screen + dragging + touchscreen + pictorialregister + movement-with-the-device etc. as a way of thinking; and iv)the changing ways in which body and MDT interact should transform teaching, learning, and research processes.

\section{il. Body-Extension Technologies: Some Singularities of MDT}

Progress in digital mobile technologies has changed the way to be in the world of the living and, consequently, to learn, to teach, and to do research. Social-technology arises with technology. For instance, we have moved from a communicative logic that is centralized and directed from one to all to a dynamic logic where the device works from every user's handling. In other words, we move from a vertical to a horizontal

\footnotetext{
${ }^{3}$ Science, Technology, Engineering, and Mathematics.

${ }^{4}$ Whenever I refer generically to touchscreen manipulations, I include 1) different ways of touching the screen (single or double click, dragging, zooming, etc.), 2) handling the device itself, 3) from it, or, 4) possible gestures that can coexist in the interactive and discursive scenario, as illustrated in Figure 2.
} 
and spreading way to look for information, interact, and deal with the device.

Unlike conventional or early cellphones, smartphones have become sensorial and perceptive extension of our body. With our smartphones, we perform a set of activities, i.e., instant sharing of information, production of various contents, application downloads, which would not have been possible with a mobile phone without connection or media integration. As they are extensions of our bodies, MDT runs through us, and we run through them. With them, we consciously or unconsciously build our ways of being, of moving, and not necessarily within our physical bodily dimension.

The singularity of mobility with touching must be taken into account because our brain keeps adjusting to what is being offered to it (Damásio, 2010), and interfaces with touching on the screen are bringing new configurations to the brain. We must see our body as the mind that understands our thinking, our feeling, and our acting (Damásio, 2004). If the body and the brain interact intensely between each other, the organism that they constitute interacts in a similar way with the surrounding environment, and we can measure their relations by the movement of the organism and the sensorial equipment (Damásio, 1996).

Anatomic changes in our brain take place all along our lives, fostering capacities, abilities and the personality itself that an individual forges and develops (Mora, 2017). Our minds, our bodies, and the physical environment work in a constant synergy (Moore-Russo \& Viglietti, 2014). Physical space (like the classroom) includes different apparatus or systems (technological, cognitive, cultural, etc.) with which we deal. Their entrance into our life (and body) alters our way of being in the world (IHDE, 2002). The way we take possession of technologies is in constant interaction with the environment. In other words, technology affects it, which in turn reacts with or over technology (Maturana \& Varela, 2001). Our physical medium also reconfigures itself.

Convergence and ubiquity arise thanks to the progress in digital technologies, particularly due to the possibility of network connection. Both convergence and ubiquity transform, dialectically, the individuals as well as their community. An application, designed for an individual user, is constantly being remodeled, based on the users' performing needs and demands. Therefore, the interaction that will be helping this reconfiguration is not only of the human individual with the machine, but of the human with other humans, and not necessarily with the device itself, but with the different spaces frequented by the individuals. Somehow, our subjectivity travels between the individual and the collective, and the borders are flimsy.

MDT is also forms of memory, our expanded memory. How many telephone numbers do we currently have to memorize? Does it make sense to store such data? Of the great amount of information (written, visual, pictorial, etc.) that circulates on the Internet, which types are important to keep stored? Never mind! We know how to locate it! But we do need to develop varied forms of processing and analyzing content, we need to build interactive procedures, and we need to construct argumentative practices in our life with others.

Although memory is one of the aims of study in the field of neuroscience and mathematics learning, I would like to focus on the importance of images and some reconfigurations in our cognition and communication with the MDT. Just as binoculars brought a new dimension to our way of seeing, gestures reveal a new realm of the mind: the imagery of language (McNeill, 1995), i.e., those linguistics aspects that refer to signs born from visual images.

Mobile devices come to insert another imagery spectrum in our interactions: the manipulations we do when we interact with a device or a person, both close and far. In the example below, I am showing an example of a gesture that, although not performed with a MDT, has come to exist in our daily midst thanks to technological advances.

\section{ili. Images, Gestures, and Simulations}

Strongly impregnated by MDT in human life (and body!), interaction widens its spectrum and becomes a communicative action materialized in various discursive modes among humans and humans or humans and nonhumans. In our personal and professional activities, we often interact in different ways. When I touch the smartphone screen, I interact with the device. If there is some kind of reaction, there is interaction, in this case, human-device. Nevertheless, with the progress of digital technologies and the imagistic potential there is a set of shared actions, experiences that are simulated and interpreted collectively. Those actions are typically situated, and the contextual character of experience in the environment reflects itself in the situated aspect of the representations that underlie simulation (Barsalou, 2009).

As the brain is the captive audience in our body, there is a flow of images (visual, auditory, olfactory, gustatory, etc.) which we trigger when we mobilize objects from outside the brain towards its interior and, when we reconstruct objects from memory, from inside towards the outside. This flow, which we can represent pictorially, but which can also include words and abstract symbols (not represented with simple images), can be called thought (Damásio, 2005). This neuroscientist also emphasizes:

The enhancement of minds through feelings and subjectivities, through image-based memory and through the capacity to link them into narratives that 
are likely to have started as non-verbal sequences, as in a film, but which have ended up, after the emergence of verbal languages, combining verbal and non-verbal elements (Damásio, 2018, p. 87-88).

Any symbol we may conceive is an image. It is our mind's currency. It is not static, and it does not refer solely to visual imagery (Damásio, 2005). This author relevantly points out that it is not possible to conceive cultural minds without the production of images, affection and reasoning -the main partakers in cultural processes. Cultural minds require the generation of images (Damásio, 2018).

In the case of mathematical thinking, we need to consider that a concurrence of gesture + speech + construction-on-the-screen + dragging + touches + pictorial-register + movement-with-the-device + movement-with-the-body compose, with the same relevance, the linguistic-cognitive spectrum of the subject (Bairral, 2017). Through this flow of images, our brain builds various mappings, and interaction becomes increasingly crucial in our learning process. Although manifestations through images are commonly difficult to be captured or analyzed synchronically, we cannot value only written registers, as often occurs in traditional teaching practices in mathematics.

All this pictorial flow, also made of words and abstract non-visual-image related symbols, can be called thought (Damásio, 2010). This imagery enhancing has come to include the capacity to invent and produce intelligent creations, which Damásio (2018) calls creative intelligence. To those interested in football, here is an example from the Video Assistant Referee (VAR).

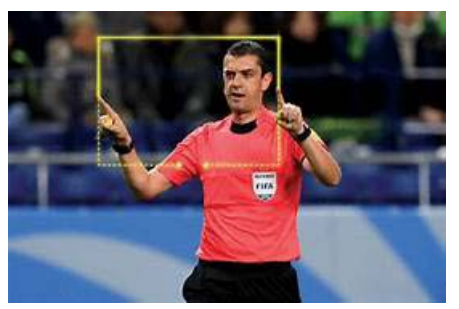

Source: Google Picture

\section{Figure 1: Referee gesturing}

There is an image flow associated with a rectangular shape, supposedly a screen. The referee (the simulator ${ }^{5}$ ), mimicking a rectangular screen, is asking to see the video. As a simulated action (Barsalou, 2009), this gesture represents a specific instance of a category (the use of VAR in a football game).Still, it may also represent groups of individuals in a more generic manner. In other words, many additional simulators develop to typify properties, relations, events, and mental states relevant to VAR (e.g., screen, flat, shape, area, going back and forward in time, winning or losing, etc.).

In this case, we have an iconic gesture (McNeill, 1995) ${ }^{6}$. As the referee's expression bears a direct relation to what he requests. It is also worth noting that

\footnotetext{
${ }^{5}$ According to Barsalou (2009), a simulator is a distributed system throughout the brain's feature and association areas that accumulate and integrate modal content processed for the category. Simulation constitutes a form of computation throughout diverse forms of cognition. It is the re-enactment of perceptual, motor, and introspective states acquired during experience with the world, body, and mind. There are multi-modal ways to express simulation. A simple computational mechanism in the brain supports a broad spectrum of processes from perception to social cognition.

${ }^{6}$ Type of gesture in the narrative realm of discourse. A pictorial gesture that represents an event or concrete object, in this case, a screen, a rectangular shape. It is a form of communication that bears a direct relationship with the context. In this particular example of the referee at the soccer game, this gesture means requesting the reviewing of the scene.
}

this new gestural simulation becomes integrated into our neurobiological spectrum and, as such, becomes a reenactment of perceptual, motor, and introspective states acquired through our experiences with our surroundings, our bodies, our minds (Barsalou, 2009).

In this scenario of visual imagery Hostetter and Alibali (2008) highlight that it may involve simulated action when the simulated perception or its features are closely tied to action. For instance, an image of a rectangle likely implies the simulation of the actions typically performed with a rectangular shape (video screen). Some signs are strongly related to handling because the perception of the characters depends on action (e.g., hands and body referee movements), or because the feature determines the actions that are afforded by the object (e.g., some specific position on the soccer field).

It is also stimulating to interpret how the referee gestures to mimic the rectangular representation. He starts with both hands at one point (usually mimicking an upper center point on the screen), and after covering the distance or the sides of this imaginary rectangle, he finishes at the symmetrical opposite (lower side) ${ }^{7}$. We are therefore dealing with interpretation, elaboration, and memory of images, mental processes that "carry with

\footnotetext{
${ }^{7}$ See the stretch from 2:14 - 2:19 in the video available at https://www. youtube.com/watch?v=pp431Y1EqfOAccess: 11 Jun. 2019
} 
them a specific mark, a unique impression, indicating that who is building and remembering something is yourself and not anybody else" (Marques, 2018).

To those who are unfamiliar with the practices of soccer, let me mention that at some given moment, the supporters' brains have registered this kind of record. Those registers can later be evoked with the appropriate stimuli. For instance, you are in a restaurant sitting near a TV that is broadcasting a soccer game. Undoubtedly, if VAR was needed while you were watching TV, your brain mapped ${ }^{8}$ this image in device space. Somehow, you can recall this performance of VAR later on.

Simulations produce inferences and predictions about a category's perceived instances using the pattern completion inference mechanism. When simulations of events occur over time, they may often only include a small subset of the mapped points within the temporal sequence, rather than being a complete reenactment of all dots (Barsalou, 2009). Through this magnetic flow, our brain builds various mappings, and interaction comes to be increasingly paramount in our learning process, as we can keep the mental processes that involve reasoning and creativity, even when we are engaged in something else (Damásio, 2010).

Based on Damásio, Marques stresses that "what we store in the device space are mechanisms that allow the summoning and reconstruction of a given object" and its transformation to be made available in the image space, "but which does not allow us to obtain a detailed description of it (Marques, 2018). The multiplicity of maps that our mind has access to ultimately makes us unaware of unfocused ${ }^{9}$ images, those images that, although they are associated with thought, are evoked outside of the mainstream of thinking, a shaping of images that apparently do not show any direct relationship with the object with which the interaction is taking place at the moment. An instance of this would be the images of having to get my car at the repair shop when I am writing an article about mathematics teaching. In other words, while acting, further actions occur in parallel, but your mind is not focused on those parallels that commonly occur (Marques, 2018).

\footnotetext{
8 According to Damásio (2005) the relationship between mental images and the brain assumes an image space (where sensorial images of all kinds explicitly occur, including manifest mental contents that central conscience allows us to know) and a device space (where device memories contain records of implicit knowledge, based on which we can build images through evoking, generate movements and facilitate the processing of images).

${ }^{9}$ The concept of unfocused images refers to the shaping of images, which do not show any direct relationship with the object with which the interaction is taking place at the moment.
}

Although the example of VAR has no direct relationship with MDT, it serves to illustrate the constant synergy among body, physical environment, and technologies. Not only the gesture referring to the rectangular shape, but the referee's addressing a specific place and specific people to request the VAR constitute a creative process that generates new images, concepts and they come to take part in people's cultural span and, consequently, they reconfigure Mathematics. How about the manipulations we do with a smartphone, that is, the touching we do on its screen or the handling and various movements we do with it and with our body?

\section{Touching on the Screen, - With the SCREEN, OR FROM THE SCREEN}

An MDT's mobility, ubiquity, and convergence imply a new comprehension and interaction between person-environment and all the knowledge building, from simple to complex, from nonverbal imagery to verbal and literary expressions, according to Damásio (2005), "depending on the capacity to map what happens along time, within ${ }^{10}$ our organism, around our organism, for and with our organism, one thing after the other, causing something else, infinitely" (p. 243).

Touching on the screen generates a network of varied movements, combining themselves, often forming a multifaceted symbolic system (Bairral, 2017). Ubiquity and mobility in a tablet or smartphone imply a better understanding and interaction subjectenvironment, and, in this sense, the expansive dimension of technology in the process of conceptual holding is still more in demand. Although the possibility to interact with the device by touching the screen is not recent (e.g., ATMs), the mobility, the types of sensitivity and performance offered by some machines are new, and have made an impression on us. Screen touches on mobile interfaces are not cognitively the same as mouse clicks (Arzarello, Bairral, \& Dané, 2014).

Some touches that we make on the screen can be related to gestures (make a zoom, double touch, flick, for instance). Others are not limited to specific gestures (McNeill, 1995) and they open up a whole new agenda for research about manipulation, either originating from it, or directly operating on it. They constitute the expression or simulation of some mental process. Although they belong to a realm of the language that materializes in images (not necessarily sounds), these manifestations do not restrict themselves to gestures or kinetic expressions. Gestures, touches, and other ways of manipulation on, with or from the screen express thought, and they must be considered as one integrated and dialectic system (McNeill, 2002).

\footnotetext{
${ }^{10}$ Italics in the original.
} 
In agreement with McNeill (2002), we believe that conjunction gesture + speech + constructionon-screen+trackings ${ }^{11}$-on-screen+touching + gesture + speech+registering-some-record make up a person's cognitive-linguistic spectrum. I understand it is extremely relevant to consider and value this joint production. There are communicative situations in which the subject limits itself to speech, or writing, or screen manipulation, for instance. We must see this combination in an inherently unstable dialectic (McNeill, 2002). Instability, the author stresses, implies stillness, but being still is also a new beginning. Dialectic (instability, stillness, restarting) makes learning highly likely with a mobile device.

Touches on-screen form another language. Therefore, they possess particularities and implications regarding our thinking. Just as usual gestures (pointing, thumbs up, etc.) that we use to communicate, the manipulations on the screen of a mobile device constitute a way to make thought visible and materialize it in a communicative act, fostering interaction.
Screen touches form a set of inputs and outputs with the fingers and thumbs that provoke immediate feedbacks on the device screen (Arzarello et al., 2014). Although the reaction (in/out) on the screen may have a device performance, we must remember that our organism does not only capture information from surroundings. On the contrary, "it builds a world, by specifying which configurations from the environment are disturbances, and which changes they trigger in the organism" (Maturana \& Varela, 2001, p. 188). What we have, then, is a world of meaning being built and not determined a machine, but by interpreting, unsettling, (re)actions, affections, etc. from the people involved. We are dealing with a performing scene that engenders subjectivities, not a MDT performance or isolated observations.

Touchscreen manipulations are human actions, embodied, simulated (Hostetter \& Alibali, 2008), cultural and multimodal, which also reveal the learners' thoughts and possess particularities. Let's have a look at that.

Chart 1: Particularities and similarities between gestures and touchscreen

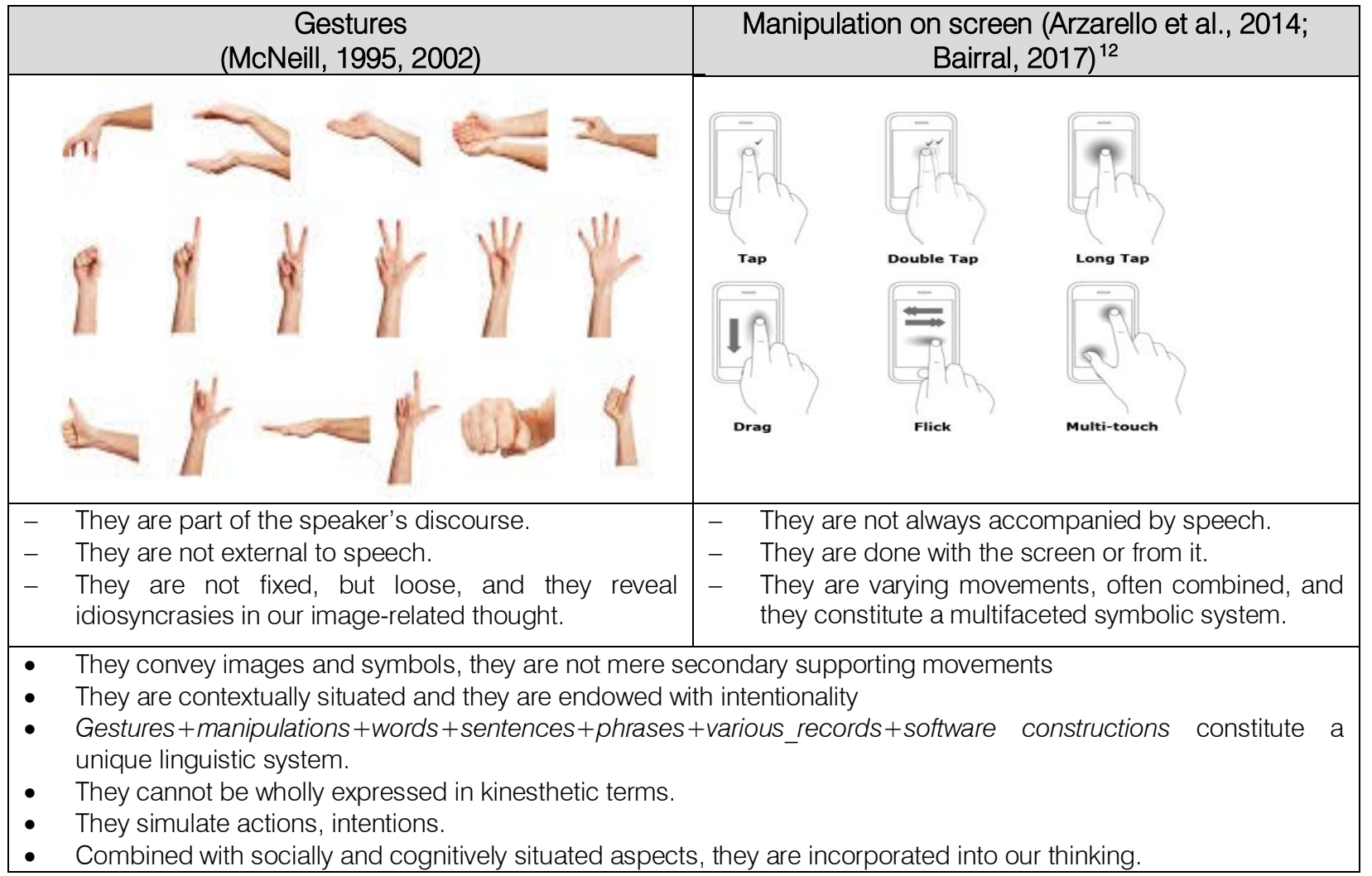

\footnotetext{
${ }^{11}$ According to Choi (2008) quoted by (Park, Lee, \& Kim, 2011) there are six basic input types by finger action on a touchscreen user interface: tap, double tap, long tap (hold), drag, flick and multi-touch. We first took those inputs into account and carried out our research focusing on mathematical thinking.

${ }^{12}$ The tracks allowed from dynamic geometric environments like GeoGebra are not touches. Still, they are equally for conceptual understanding and thinking.
} 
The manipulations that we perform on screen have various communicative intentions, which also have particularities related to the cultural context in which they are produced. Although the performance or reaction to touch is related to the quality of the device, the initial manipulation or input, and the response to it do not vary in terms of intentionality and interpretation. For instance, when I observe a person from a distance sliding their finger towards the right or left, I can interpret that they are changing the content of the screen. In other words, the observer can infer the type of response that the user wishes through the kind of screen handling.

As the referee's gestures, touching the screen can be done through specific movements, situated and intentional. Some touches on the screen, as the six ones illustrated in Chart 1, also simulate the user's actions and intentions (Hostetter \& Alibali, 2008). Another observer can interpret and infer such handlings. Relations among screen touching and gestures are also conditioned to the performance of the device that is being used. They are contingent on current configurations of sensory perceptions (Sinclair \& de Freitas, 2014).

If there is one type of manipulation that we perform most often with our smartphones, it is rotating. Every rotation is oriented (Kruger, Carpendale, Scott, \& Tang, 2005). We turn the screen to better visualize some image or video. We move the device to connect the charger, for instance. Sometimes, among other gyrating actions that we perform, we turn our bodies with the smartphone to share or interact with our interlocutor. You can find some examples of these actions in Figure 2.

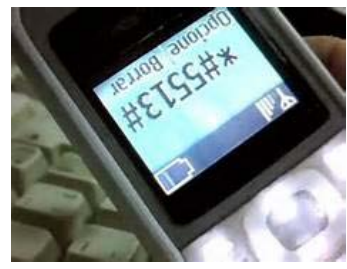

a) Turning the device

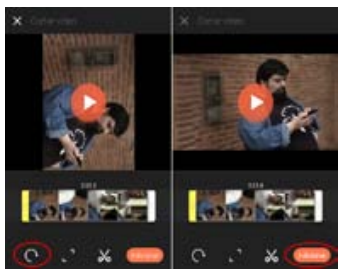

b) Rotating the screen

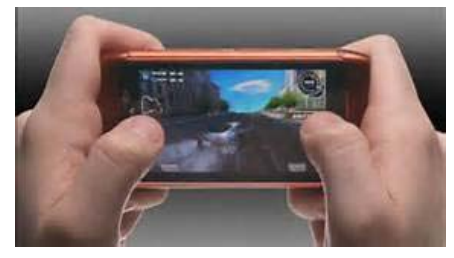

c) Playing, turning around

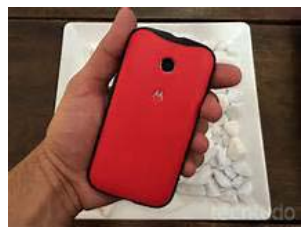

d) Turning over the device in order to clean, replace cover, batteries, etc

Source: Author's elaboration with images from Google Pictures

Figure 2: Some rotating actions that we perform with our smartphone

The act of turning involves orienting. Many devices require other objects to be turned or transported. Studies of kinetic movements show that gyrating and moving are inseparable in the real world, and researchers, as Kruger et al. (2005) stress three advantages of interaction in these actions: understanding, coordination, and communication.

Although the rotating movements we perform in our daily lives (turning the body when practicing some sport or dancing, visualizing a printed map, etc.), may not necessarily be the same as the ones with MDT, the latter have come to include a new spatial, sensorial and cognitive configuration in our current actions. According to Hostetter \& Alibali (2008), it is relevant to understand plan movements, text, and create mental images by utilizing the same perception and action mechanisms that we use for interacting with the world. Thus, we accomplish language processing and mental imagery through simulations that activate or re-instantiate perception and action states.

In this respect, Damásio (2005) also reminds us that when we evoke an object, we do not retrieve only sensorial data. We recover motor and emotional information as well. We do not only evoke the sensorial characteristics of a real object but the past exchanges and reactions we had with that object.
When approaching our conceptual understandings, which are situated, Barsalou (2009) comments that they are not necessarily conscious. In fact, according to this author, they are more unconscious than otherwise. These re-enactments can happen through perception, memory, conceptualization, understanding along conscious (re)organizations. She adds that when these (re)enactments reach awareness, they can be seen as composed mental images, as imagination is typically a conscious deed.

Therefore, rotation and translation or directed shifting ${ }^{11}$, with or without a smartphone, are materialized and frequently occur in our daily lives, and, although they can be done without an explicit mathematic cognition or awareness on the part of the performer, these movements represent simulations (Barsalou, 2009). We can analyze them from a mathematics point of view.

Although some screen touching manipulations seem to click and to drag movements (as we do in software like GeoGebra or program controls), they present differences in terms of orientation, as illustrated in Figure 3.

\footnotetext{
${ }^{13}$ Along a segment, a vector.
} 


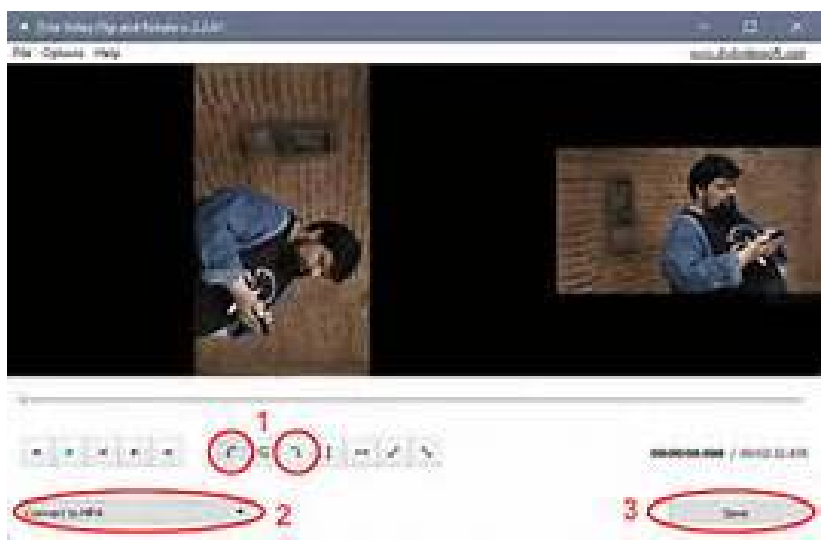

Source: Google Pictures

Figure 3: Image rotation through icon control

The possibility of handling more than one finger has been inciting, as we believe that simultaneous movement of several elements (angles, sides, etc.) in a figure -through isolated or combined touches- can bring forth changes in the construction of mathematics knowledge. In Figure 3, we have an example of manipulation with the screen, or rather, with the device and, sometimes, with the body.
Different studies we have undertaken (Assis, 2020; Assis \& Bairral, 2019; Bairral, Arzarello, \& Assis, 2017) have allowed us to capture, map and analyze in detail some screen touches and some mathematics actions involved in rotating movements and with specific mathematics tasks. Chart 2 illustrates the mapping of our observations.

Chart 2: Mapping of touchscreen (Assis, 2020)

\begin{tabular}{|c|c|c|c|}
\hline \multicolumn{2}{|c|}{ Manipulation } & Touches & Action \\
\hline & 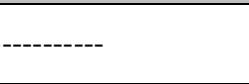 & & $\begin{array}{l}\text { Pausing, analysis, reflection } \\
\text { observation, negotiating }\end{array}$ \\
\hline \multirow{3}{*}{ Touching } & Simple & & $\begin{array}{l}\text { Selecting some element in } \\
\text { the construction or touching } \\
\text { on a working area }\end{array}$ \\
\hline & Simple and fixed & & $\begin{array}{l}\text { Selecting some element } \\
\text { and time to analyze }\end{array}$ \\
\hline & Double & & $\begin{array}{l}\text { Selecting some hidden tool } \\
\text { (but not keeping it fixed) }\end{array}$ \\
\hline \multirow{6}{*}{ Dragging } & Upwards & & $\begin{array}{l}\text { Selecting an element or } \\
\text { construction and dragging it } \\
\text { upwards }\end{array}$ \\
\hline & Downwards & & $\begin{array}{l}\text { Selecting an element or } \\
\text { construction and dragging it } \\
\text { downwards }\end{array}$ \\
\hline & to the left & & $\begin{array}{l}\text { Selecting an element or } \\
\text { construction and dragging } \\
\text { to the left }\end{array}$ \\
\hline & to the right & & $\begin{array}{l}\text { Selecting an element or } \\
\text { construction and dragging it } \\
\text { to the right }\end{array}$ \\
\hline & Expanding & & $\begin{array}{l}\text { Zoom out to have a better } \\
\text { view of the construction }\end{array}$ \\
\hline & Reducing & & $\begin{array}{l}\text { Zoom in to have a better } \\
\text { view of the construction } \\
\text { area, the construction itself } \\
\text { as a whole or other related } \\
\text { elements }\end{array}$ \\
\hline Rotation & With one finger & & Free rotation \\
\hline
\end{tabular}




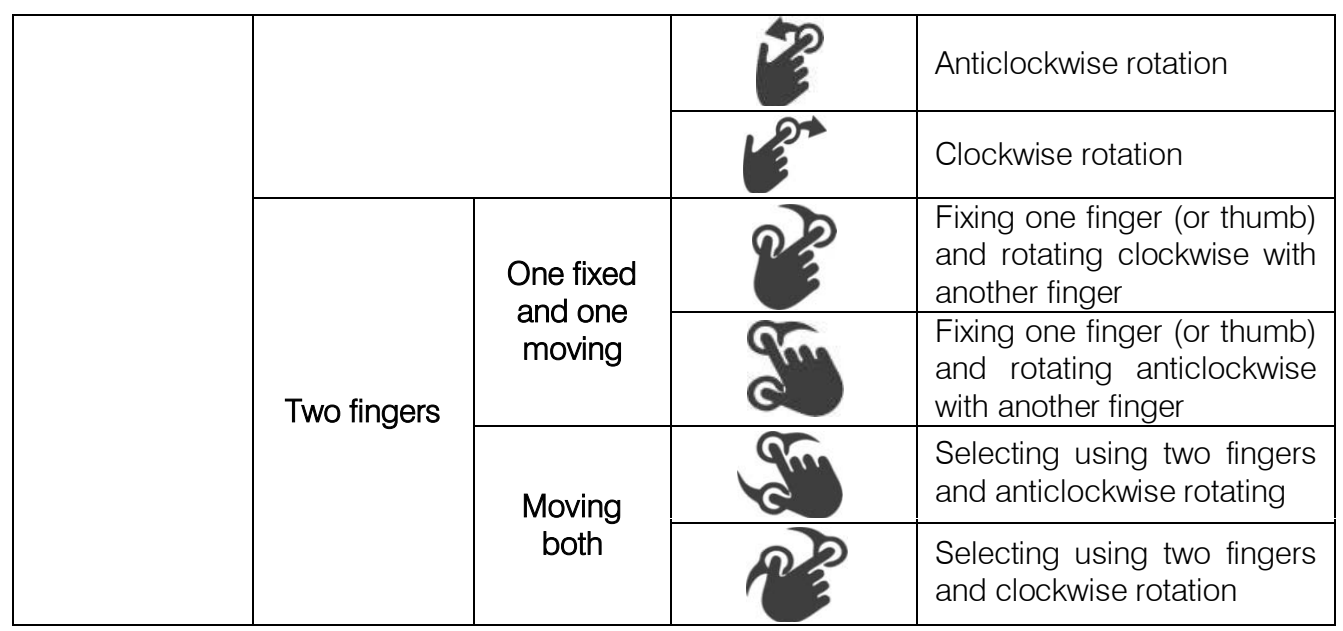

In this mapping, we can consider the (isolated or articulated) performance of touches. As an embodied process, screen touches combine productively to generate infinite conceptual combinations (Barsalou, 2009). Didactically, identifying the type of touch and its particularity in the development of mathematical reasoning is important due to the type of task which has to be designed according to the teacher's aims. In other words, teachers need to be aware of the singularity of each kind of touch when proposing tasks that aim to trigger the students' intrinsic motivation to work into mathematics activities that enhance findings, reflections, and the development of mathematical thinking in its various aspects (Bairral et al., 2017).

Like gestures, touchscreen also occur as the result of simulated action and sensory perception, which are the bases of mental imagery and language production (Hostetteer \& Alibali, 2008). Taking into account the performance, i.e., the speed of the response from the device, when we execute manipulations on MDT only as touches on screen (Chart 2), it depends on three factors: space, that is, the area on which the touch is being performed or can be performed; sustained action of movement, with possible combinations of different types of touches; and simultaneous movement of several elements on the screen (Assis; Bairral, 2019).

In the same way that simultaneous screen touches of points on the screen brings about implications of an epistemological order, it also makes our cognitive structures more complex, for example, through the simultaneous motion of various elements (e.g., angles, sides, area, etc.) in a figure. Another issue that we need to consider is the way using an MDT allows alterations on the task design. (Bairral et al. 2017).

\section{Concluding Remarks}

Acknowledging that different technologies contribute differently to our way of living, communicating, and learning, in this article, I have tried to enhance the gestures approach by bringing contributions from cognitive science and neuroscience. Therefore, I advocate that manipulations on or with the screen constitute a new and challenging way of language manifestation and become a part of our embodied cognition (Bairral, 2019).

I focused on-screen touching. Although the possibility to touch the screen is not new in itself, mobility, ubiquity, and the type of sensitivity and performance offered by MDT are recent, and they have affected us. The changes they have brought about are part of human development, and that involves creation and innovation. Therefore, screen touching actions are not a minor help to our thinking process. They are leading actors and, in fact, they effectively materialize, together with other forms of language, our thinking, and our communication.

I hope I have convinced you that touchscreen actions are a new field of language and cognition manifestation. Gestures, touching, and other forms of manipulation on, with or from the screen express some kind of thought, and we should consider them all as a single dynamic and dialectic system (McNeill, 2002). They are new and different movements that we do with our hands, fingers, or body and that come to compose and transform our flow of images, interaction, thinking, and existence.

Considering the dialectic in the triad instability, rest, and restarting, when a subject manipulates a mobile device in mathematical tasks, it is substantial to look the conjunction (gestures+touches +tracks+ writing+construction_on_screen) in the construction of mathematical knowledge, without prioritizing one of them, namely writing. In other circumstances, we may prefer different forms of records, including writing and constructions on software, which will lead us to other types of knowledge.

The presence of MDT, like any other new technology, brings a number of challenges, fears, 
insecurity, unsettling, and controversies. I decided simply to propose some insights which can be promising for the enrichment in our way of thinking and interacting. I shall leave the task of judging on its being good, bad, favorable, useful, etc. onto the reader.

The reader may be wondering what the two examples that I have shown here (VAR and rotation movements) have to do with mathematics. They are not cases often used; that is, they are not among the prescribed contents of didactic manuals. Nevertheless, if we understand that mathematics is a human construction and, therefore, it evolves and recreates itself, we have a process of meaning into play. Nowadays, the great challenge is to produce new mathematical concepts and powerful strategies of thinking. Dynamic and inventive processes should move us. We are much more than prescribed contents, procedures, routines, or formulae.

Writing this article at a time when the world is going through such critical moments concerning public biological, social, and emotional health has not been easy. Research in the field of Humanities is necessary, contrary to what some world leaders advocate. Every life matters! This article is my homage to those who defend life by producing knowledge as, with and for Humans and not only as Machines.

\section{References Références Referencias}

1. Arzarello, F., Bairral, M., \& Dané, C. (2014). Moving from dragging to touchscreen: geometrical learning with geometric dynamic software. Teaching Mathematics and its Applications, 33(1), 39-51. doi:10.1093/teamat/hru002

2. Assis, A., \& Bairral, M. (2019). Using touchscreen devices to improve plane transformation in high school classroom International Journal for Research in Mathematics Education (RIPEM), 9(1), 45-60.

3. Assis, A. R. de. (2020). Alunos do Ensino Médio realizando toques em telas e aplicando isometrias com GeoGebra. [High School students performing touchscreens and applying is ometries with Geo Gebra]. Doctoral Thesisin Education.Seropédica, Rio de Janeiro: UFRRJ/PPGEduc.

4. Bairral, M., Arzarello, F., \& Assis, A. (2017). Domains of manipulation in touchscreen devices and some didactic, cognitive and epistemological implications for improving geometric thinking. In G. Aldon, F. Hitt, L. Bazzini, \& U. Gellert (Eds.), Mathematics and technology: a C.I.E.A.E.M source book (pp. 113-142). Hamburg, Germany: Springer.

5. Bairral, M. A. (2017). As Manipulações em Tela Compondo a Dimensão Corporificada da Cognição Matemática [The Manipulations on Screen Composing the Embodiment Dimension of the Mathematical Cognition]. Jornal Internacional de
Estudos em Educação Matemática (JIEEM), 10(2), 104-111.

6. Bairral, M. A. (2019). Dimensions to be considered in Teaching, Learning and Research with Mobile Devices with Touchscreen. Acta Scientiae, 21 (2), 93109. doi:10.17648/acta.scientiae.v21iss2id5040

7. Barsalou, L. W. (2009). Simulation, situated conceptualization, and prediction. Philosophical Transactions of the Royal Society of London: Biological Sciences(364), 1281-1289. doi:10.1098/ rstb.2008.0319

8. Damásio, A. R. (1996). O erro de Descartes: emoção, razão e o cérebro humano [Descartes' Error: Emotion, Reason and the Human Brain] (V. G. Segurado, Trans.). São Paulo: Companhia das Letras.

9. Damásio, A. R. (2004). Em busca de Espinosa: prazer e dor na ciência dos sentimentos [Looking for Spinoza: joy, sorrow and the feeling brain] (L. T. Motta, Trans.). São Paulo: Companhia das Letras.

10. Damásio, A. R. (2005). O mistério da consciência: do corpo e das emoções ao conhecimento de si [The feeling of whathappens: Bodyandemotion in themakingofconsciousness](L. T. Motta, Trans. 9 ed.). São Paulo: Companhia Das Letras.

11. Damásio, A. R. (2010). O livro da consciência: A construção do cérebro consciente[Self Comes to Mind: Constructing the Conscious Brain] (L. O. Santos, Trans.). Porto: Temas e Debates.

12. Damásio, A. R. (2018). A Estranha Ordem das Coisas. As Origens Biológicas dos Sentimentos e da Cultura [The Strange Order of Things: Life, Feeling, and Making of Cultures] (L. T. Motta, Trans.). São Paulo: Companhia das Letras.

13. Hostetter, A. B., \& Alibali, M. W. (2008). Visible embodiment: Gestures as simulated action. Psychonomic Bulletin \& Review, 15(3), 495-514.

14. Ihde, D. (2002). Bodies in Technology. Minneapolis London: University of Minnesota Press.

15. Kruger, R., Carpendale, S., Scott, S. D., \& Tang, A. (2005). Fluid Integration of Rotation and Translation. Paper presented at the Proceedings of the ACM Conference on Human Factors in Computing Systems (CHI)'05, April 2-7, 2005, Portland, Oregon, USA, pp. 601-610.

16. Marques, W. (2018). Multinumeramentos em smartphones de alunos do Ensino Médio sob telas da neurociência [Multinumeracy on High School students' smartphones under neuroscience screens]. Doctoral Thesis in Education. Seropédica, Rio de Janeiro: UFRRJ/PPGEduc.

17. Maturana, H. R., \& Varela, F. J. (2001). A árvore do conhecimento: as bases biológicas da compreensão humana [The tree of knowledge: the biological bases of human understanding] $(\mathrm{H}$. 
Mariotti \& L. Diskin, Trans.9 ed.). São Paulo: Palas Athena.

18. McNeill, D. (1995). Hand and mind: What Gestures reveal about Thought. Chicago and London: The University of Chicago press.

19. McNeill, D. (2002). Gesture and Language Dialectic. Acta Linguistica Hafniesia, 1-25.

20. Moore-Russo, D., \& Viglietti, J. M. (2014). Embodied cognition across dimensions of gestures. Considering Teachers' responses to ThreeDimensional Tasks. In L. Edwards, F. Ferrara, \& D. Moore-Russo (Eds.), Emerging perspectives on gesture and embodiment in mathematics (pp. 137227). New York: Information Age Publishing.

21. Mora, F. (2017). Cómo funciona el cerebro [How the brain works] (5 ed.). Madrid: Alianza.

22. Park, D., Lee, J., \& Kim, S. (2011). Investigating the affective quality of interactivity by motion feedback in mobile touchscreen user interfaces. International Journal of Human-Computer Studies, 69(12), 839853. doi:10.1016/j.bbr.2011.03.031

23. Sinclair, N., \& de Freitas, E. (2014). The haptic nature of gesture: Rethinking gesture with new multitouch digital technologies. Gesture, 14(3), 351374. doi:10.1075/gest.14.3.04sin 